\section{EXTRAÇÃO DO ÓXIDO DE TITÂNIO DE ILMENITA SEM A GERAÇÃO DE RESÍDUOS TÓXICOS}

\section{Autora: Renata de Cássia Camara \\ Orientadores: Orientadora: Prof. ${ }^{a}$ Dr. Marli Teixeira de A. Minhoni Co-orientador: Prof. Dr. Ademércio Antonio Paccola}

\section{Instituição de Fomento}

FAPESP - Fundação de Amparo à Pesquisa do estado de São Paulo

\section{Nome da Instituição}

Universidade Estadual Paulista "Júlio de Mesquita Filho"

E-mail de contato: camararenata@fca.unesp.br

Palavras-chave: Bactérias, IImenita, Titânio.

\section{INTRODUÇÃO}

O elemento titânio é um mineral que apresenta elevada resistência à corrosão sendo, utilizado em vários equipamentos industriais, próteses ósseas, implantes dentários e instrumentos cirúrgicos. O dióxido de titânio $\left(\mathrm{TiO}_{2}\right)$ é muito utilizado em tintas, pelo alto poder de fixação. O Brasil possui uma das maiores reservas mundiais de titânio na forma de Anastásio $\left(\beta-\mathrm{TiO}_{2}\right)$, nos estados de Minas Gerais e Goiás. Outros depósitos de titânio são os de ilmenita e os de rutilo $\left(\alpha-\mathrm{TiO}_{2}\right)$ em Mataraca, estado da Paraíba (TOLEDO et al.,2004).

A ilmenita é o mineral mais utilizado para extração do $\mathrm{TiO}_{2}$ (RÉ \& MARQUES, 2002), Esse mineral é um titanato de $\mathrm{Fe}(\mathrm{II}), \mathrm{FeTiO}_{3}$ podendo possuir também variáveis de $\mathrm{Fe}$ (III) e outros elementos, tais como Al (Alumínio), Ca (Cálcio), $\mathrm{Cr}$ (Cromo), Mg (Magnésio), Mn (Manganês), Nb (Nióbio) , P (Fósforo), Si (Silício) e V (Vanádio).

De acordo com Sarker et al (2006), o processo de produção industrial do $\mathrm{TiO}_{2}$ mais utilizado é o chamado processo sulfato (hidrólise térmica), que emprega $\mathrm{H}_{2} \mathrm{SO}_{4}$ concentrado e ocorre através das seguintes etapas: abertura do minério, clarificação e filtração, hidrólise térmica, lavagem e filtração, secagem e calcinação, acabamento e 
moagem. Outros processos envolvem a fusão com substâncias de caráter ácido $\left(\mathrm{KHSO}_{4}\right.$, $\left.\mathrm{Na}_{2} \mathrm{~S}_{2} \mathrm{O}_{7}\right)$; alcalinas $\left(\mathrm{KOH}, \mathrm{Na}_{2} \mathrm{CO}_{3}, \mathrm{CaO}\right)$; redutoras $\left(\mathrm{C}, \mathrm{S}_{8}\right)$ ou complexantes $\left(\mathrm{CaF}_{2}\right.$, $\mathrm{NH}_{4} \mathrm{~F}, \mathrm{NH}_{4} \mathrm{HF}_{2}$ ).

O grande problema desses processos é a considerável geração de resíduos, onde a produção de $1 \mathrm{t}$ de $\mathrm{TiO}_{2}$ sintético gera cerca de 3,5 t de rejeitos tóxicos. Associados aos metais, segundo Videla (1981) são encontrados microrganismos que estão associados aos processos de corrosão e na grande maioria são bactérias oxidantes do ferro onde através da oxidação obtém a energia necessária para seus processos vitais.

Devido aos danos que os resíduos tóxicos gerados pelos processos convencionais de separação do Ferro de Titânio na obtenção da ilmenita possam causar ao meio ambiente é de grande interesse econômico e ambiental que novas metodologias de extração do mineral sejam descobertas, uma vez que nesses já se encontram bactérias capazes de realizarem o processo.

\section{OBJETIVO GERAL}

O objetivo geral do projeto é obter o óxido de titânio de ilmentita através da ação de bactérias sem gerar resíduos poluentes.

\section{OBJETIVOS ESPECÍ́FICOS}

O Presente projeto de Pesquisa tem como objetivo presente desenvolver uma metodologia de obtenção do óxido de titânio sem a necessidade da utilização de produtos químicos que gerem resíduos tóxicos e poluentes.

\section{METODOLOGIA}

Foram realizados vários ensaios sob condições de laboratório para se estabelecer um padrão no processo de separação do ferro e obtenção da ilmenita. O solo utilizado no trabalho foi coletado na Fazenda experimental Lageado, sendo um solo classificado como Latossolo Vermelho escuro de acordo com Carvalho et al. (1983), e na classificação da Embrapa (1999), Latossolo Vermelho (LV). A separação das partículas do solo foi 


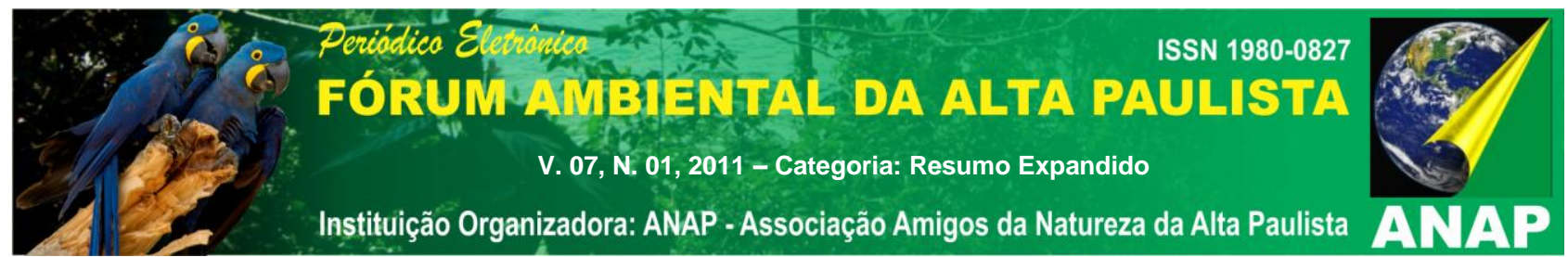

realizada através da metodologia rotineira de peneiramento, técnica utilizada no laboratório de geoquímica da FCA (Faculdade de Ciências Agronômicas).

O peneiramento foi relizado até se obter a ilmenita, que foi distribuída em várias quantidades em tubos de ensaios, contendo água destilada, solução de sacarose $\mathrm{C}_{12} \mathrm{H}_{22} \mathrm{O}_{11}$, cloreto de amônia - $\mathrm{NH}_{4} \mathrm{Cl}$ e diamônio fosfato - DAP [ $\left.\left(\mathrm{NH}_{4}\right) 2 \mathrm{HPO}_{4}\right]$, como fontes de carbono, nitrogênio e fósforo. Para determinação do ferro, está sendo realizada Espectrofotometria de Absorção Atômica durante o bioprocessamento. Estes foram encubados à temperaturas que variam entre 20 e $30^{\circ} \mathrm{C}$.

Durante o processo de incubação as bactérias atuantes estão sendo isoladas, submetidas ao teste de coloração diferencial de Gram e preservadas em tubos contendo meio de cultura.

\section{RESULTADO (S)}

Diante desse período de testes do bioprocessamento foi determinado que a uma temperatura de $28^{\circ} \mathrm{C}$ ocorre uma acelerada redução de ferro da ilmenita e que um grupo de bactérias atuam nesse processo.

\section{CONSIDERAÇÕES FINAIS}

Os resíduos gerados pelos processos industriais e que lançados ao meio ambiente, trazem sérias conseqüências de contaminação ao meio afetando diretamente as diversas formas de vida existentes. Diante dessas ocorrências é de fundamental importância o desenvolvimento novas tecnologias no emprego dos processos industriais com a finalidade de evitar a produção de dejetos poluentes ao meio.

\section{REFERÊNCIAS}

TOLEDO, M.C.M., OLIVEIRA, S.M.B., FONTAN, F., FERRARI, V.C. \& PARSEVAL, P.de. Mineralogia, morfologia e cristaloquímica da monazita de Catalão I. Revista Brasileira de Geociências, v.34, p.135-146, 2004 


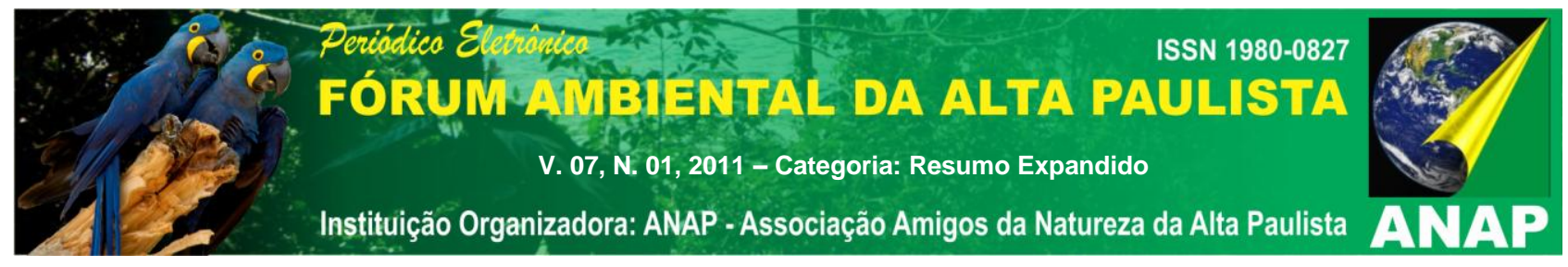

RÉ, E.R., MARQUES, M.B. Planejamento de lavra para mineração de minerais pesados para titânio. Workshop Datamine, 10. p.13, 2002.

SARKER, M. K.; Rashid, A. K. M. B.; Kurny, A. S. W.; Int. J. Min. Proc. P.223, 2006.

VIDELA, A.H. Corrosão Microbiológica. São Paulo: Edgard Blucher, p.65, 198.

CARVALHO, W. A; ESPÍNDOLA, C. R.; PACCOLA, A. A. Levantamento de solos da Fazenda Lageado: Estação Experimental. Boletim Científico da Faculdade de Ciências Agronômica. Universidade Estadual Paulista, Botucatu, n.1, p.1- 95, 1983.

EMBRAPA. Centro Nacional de Pesquisa de Solos. Sistema brasileiro de classificação de solos. Rio de Janeiro: Embrapa Solos, p.412, 1999. 